\title{
ANALISIS DAN PERENCANAAN GEDUNG ASRAMA PUTRI TAHFIDZ DESA SEI RAYA KECAMATAN BATANG TUAKA KABUPATEN INDRAGIRI HILIR
}

\author{
Nadila Mailiyani \\ Prodi Teknik Sipil, Fakultas Teknik dan Ilmu Komputer, Universitas Islam Indragiri, Tembilahan \\ Email: nadilamayliani2020@gmail.com (korespondensi)
}

\begin{abstract}
The female dormitory building in Sei Raya village, indragirihilir district is planned to fulfill government activities, namely the basic Guidelines for the 1 Village 1 Tahfidz House Program by following the DMIJPT 2019 Operational Technical Guidelines (PTO) on Tahfidz Houses. Planning for dormitory building analysis calculations using the Engilab Beam application. The length of the building is $48 \mathrm{~m}$ wide $12 \mathrm{~m}$ from the data so it is dilated. The dilatation used is two-column dilatation.
\end{abstract}

Keywords: Building, Engilab Beam, Dilation

\begin{abstract}
Abstrak
Gedung asrama putri di desa Sei Raya keabupaten indragiri hilir dierencanakan untuk memenuhi kegiatan pemerintah yaitu tentang Petunjuk dasar Program 1 Desa 1 Rumah Tahfidz dengan mengikuti Petunjuk Teknis Operasional (PTO) DMIJPT Tahun 2019 Tentang Rumah Tahfidz. Perencanaan gedung asrama analisa perhitungan menggunakan Aplikasi Engilab Beam. Panjang gedung adalah 48 m lebar $12 \mathrm{~m}$ dari data tersebut maka dilakukan Dilatasi. Dilatasi yang dipakai adalah dilatasi dua kolom
\end{abstract}

Kata kunci: Gedung, Egilab Beam, Dilatasi

\section{PENDAhuluan}

Asrama adalah hunian bersama bagi pelajar yang dibangun dalam berbagai skala, mulai dari skala kecil (sampai Asrama adalah hunian bersama bagi pelajar yang dibangun dalam berbagai skala, mulai dari skala kecil (sampai 50 penghuni) hingga skala sangat besar dengan penyediaan lebih dari 200 kamar. Di berbagai negara, asrama ini telah dirancang dan dibangun dengan standarstandar khusus sesuai dengan jenjang pendidikan penghuninya.

Standar asrama di negara lain telah ditetapkan dengan memperhatikan berbagai faktor seperti kebersihan, keamanan, standar luasan, standar kelengkapan fasilitas dan bahkan standar kebutuhan sosialisasi penghuni. Di Malaysia ditemukan panduan khusus mengenai asrama, yaitu Garis Panduan dan Peraturan Bagi Perancangan Bangunan Malaysia tahun 2008, yang mengatur jenis asrama, standar ruang asrama, termasuk penghuni bagi setiap tipe asrama. Panduan semacam ini belum ditemukan di Indonesia.

Bangunan asrama menjadi area yang perlu mendapat perhatian karena telah ada panduan internasional standar spesial asrama dalam buku-buku standar ruang, antara lain Times Saver Standard dan Architect's Data. Kajian terhadap kaitan antara desain ruang dan fasilitas asrama dengan perilaku penghuni perlu dilakukan untuk mengetahui tingkat keterkaitan antara desain dan perilaku agar nantinya dapat dilakukan kajian untuk menyusun panduan desain yang sesuai dengan kebutuhan dan karakter penghuni secara umum.

Asrama merupakan salah satu bagian gedung Tahfidz yang diperlukan untuk menghasilkan Santri dan Santriwati yang unggul. Pembangunan gedung perencanaan struktur bangunan bertingkat tinggi adalah kekuatan struktur bangunan, dimana faktor ini sangat terkait dengan keamanan dan ketahanan bangunan dalam menahan dan menampung beban yang bekerja pada struktur. Perencanaan gedung bertingkat tinggi harus direncanakan dan didesain sedemikian rupa agar dapat digunakan sebaik-baiknya, nyaman dan aman terhadap bahaya gempa bagi pemakai.

\section{TINJAUAN PUSTAKA}

\subsection{Kriteria Perencanaan}


Kriteria perencanaan asrama pondok pesantren berdasarkan standar dari NAD (Neufert Architecture Data) dan Time Saver Standards for Building Type.

Time Saver Standards for Building Types menyebutkan bahwa luas ruangan minimum untuk satu kamar dengan 2 tempat tidur tingkat yang dihuni 4 orang adalah 120 kaki persegi atau kurang lebih 11 meter persegi. Dapat dipahami juga jika di kamar tersebut ditempatkan 2 tempat tidur tidak bertingkat, maka luasan yang dibutuhkan kurang lebih sama karena angka tersebut memperhitungkan area yang dibutuhkan oleh tempat tidur. Luasan kamar asrama dipengaruhi oleh banyaknya penghuni, jumlah tempat tidur yang digunakan dan jenis tempat tidur yang digunakan. Kamar asrama yang dihuni oleh 2 atau lebih orang menggunakan tempat tidur double decker/double bunk untuk mengoptimalkan luas kamar agar dapat menampung banyak penghuni

Tabel 2.1 Indikator Volume Khusus

\begin{tabular}{|c|c|c|}
\hline $\begin{array}{c}\text { Jumlah kasur } \\
\text { dua lantai }\end{array}$ & $\begin{array}{c}\text { Jumlah } \\
\text { orang }\end{array}$ & $\begin{array}{c}\text { Minimal area yang } \\
\text { dibutuhkan }\end{array}$ \\
\hline 2 & 4 & $6 \mathrm{~m} 2$ \\
\hline 4 & 8 & $12 \mathrm{~m} 2$ \\
\hline 6 & 12 & $24 \mathrm{~m} 2$ \\
\hline 8 & 16 & $48 \mathrm{~m} 2$ \\
\hline 10 & 20 & $96 \mathrm{~m} 2$ \\
\hline 12 & 24 & $192 \mathrm{~m} 2$ \\
\hline
\end{tabular}

Sumber: (Chiara, 1975)

\subsection{Pembebanan}

Beban-beban pada struktur bangunan bertingkat, menurut arah bekerjanya dapat dibagi menjadi dua, yaitu : (PPI, 1983)

1. Beban Vertikal (Gravitasi).

a. Beban Mati (Dead Load).

Beban mati merupakan beban yang bekerja akibat gravitasi yang bekerja tetap pada posisinya secara terus menerus dengan arah ke bumi tempat struktur didirikan. Yang termasuk beban mati adalah berat struktur sendiri dan juga semua benda yang tetap posisinya selama struktur berdiri

b. Beban Hidup (Live Load).

Beban hidup adalah berat dari penghuni dan atau barang-barang yang dapat berpindah, yang bukan merupakan bagian dari bangunan. Sedangkan pada atap, beban hidup termasuk air hujan yang menggenang. Beban hidup yang bekerja pada bangunan ini disesuaikan dengan rencana fungsi bangunan tersebut

c. Beban Air Hujan.

2. Beban Horizontal (Lateral).

a. Beban Gempa (Earthquake Load). Beban gempa adalah besarnya getaran yang terjadi di dalam struktur rangka bangunan akibat adanya pergerakan tanah oleh gempa. Pertama kali di Indonesia ketetapan perencanaan gempa untuk bangunan dimasukkan dalam Peraturan Muatan Indonesia 1970, lalu peraturan ini diperbaharui dengan diterbitkannya Peraturan Perencanaan Ketahan Gempa untuk Bangunan Gedung (SNI1726-2002)

b. Beban Angin (Wind Load).

Berdasarkan Peraturan Pembebanan Indonesia untuk Gedung (PPIG) 1983 pasal 4.4.2 pada gedung tertutup dengan tinggi $\geq 16$ meter dapat diberikan pembebasan atas pengaruh angin. Beban angin adalah beban yang bekerja pada bangunan atau bagiannya karena adanya selisih tekanan udara (hembusan angin kencang). Beban angin ini ditentukan dengan menganggap adanya tekanan positif dan tekanan negatif (isapan angin), yang bekerja tegak lurus pada bidang-bidang bangunan yang ditinjau (Benny, 1996)

c. Tekanan Tanah dan Air Tanah.

\subsection{Struktur Beton Bertulang}

Struktur merupakan satuan dari salah satu ataupun beberapa material yang memiliki kekuatan menahan ataupun menopang suatu beban, baik beban mati atapun beratnya sendiri, beban hidup, beban gempa, beban angin, dan beban khusus lainya.

Beton adalah campuran antara semen portland atau semen hidraulik yang lain, agregat halus, agregat kasar dan air, dengan atau tanpa bahan tambahan yang membentuk masa padat (SNI 03- 2847 2002,Pasal 3.12).

Beton bertulang adalah beton yang ditulangi dengan luas dan jumlah tulangan yang tidak kurang dari nilai minimum yang di syaratkan dengan atau tanpa prategang, dan direncanakan berdasarkan asumsi bahwa kedua bahan tersebut bekerja sama dalam memikul gaya-gaya (SNI 03- 2847 - 2002, Pasal 3.13).

\subsection{Perencanaan Struktur Atas (Upper Structure)}

Perencanaan Atas terdiri dari struktur atap dan portal. Struktur portal merupakan satu kesatuan antara balok, kolom dan pelat lantai. Perencanaan struktur portal dilakukan berdasarkan Peraturan Beton Bertulang 
Indonesia (PBI) 1971, Standar Negara Indonesia (SNI) 03-2847-2002, dan peraturan yang terbaru yakni Standar Negara Indonesia (SNI) 2847-2013.

Seluruh prosedur perhitungan mekanika/analisa struktur untuk struktur atas dilakukan dengan Metode Cross untuk perhitungan beban vertikal dan Metode Portal untuk perhitungan beban horizontal. Dengan dua metode ini akan didapatkan gaya - gaya dalam yang bekerja pada struktur.

\subsection{Perencanaan Struktur Bawah (Sub Structure)}

Struktur bawah (sub structure) yang berupa pondasi, merupakan struktur yang berfungsi untuk meneruskan beban-beban dari struktur atas ke dalam lapisan tanah. Dalam menentukan jenis pondasi yang sesuai kita perlu mempertimbangkan beberapa hal sebagai berikut :

1. Keadaan tanah, seperti parameter tanah, daya dukung tanah, dll

Sebelum menentukan jenis pondasi yang akan digunakan, terlebih dahulu harus diketahui kondisi tanah tempat bangunan akan didirikan. Untuk keperluan tersebut, maka dilakukan penyelidikan tanah (soil investigation). Penyelidikan yang dilakukan terdiri dari penyelidikan lapangan (field test) dan penyelidikan laboratorium (laboratory test). Penyelidikan tanah dimaksudkan untuk mengetahui kondisi geoteknik, baik keadaan, jenis, dan sifat-sifat yang menjadi parameter dari tanah pondasi rencana.

2. Jenis struktur atas (fungsi bangunan)

3. Anggaran biaya yang dibutuhkan

4. Waktu pelaksanaan yang direncanakan

\subsection{Aplikasi Engilab Beam}

ENGILAB BEAM adalah software atau perangkat lunak yang digunakan untuk menganalisis analisis statis dan dinamis linier dan non linear, software ini dapat digunakan menganalisis portal dengan 2 dimensi dan 3 dimensi. Analisa struktur pada perencanaan struktur gedung ini dilakukan dengan menggunakan program ENGILAB BEAM yang merupakan salah satu program analisis struktur yang telah dikenal luas dalam dunia teknik sipil dan juga merupakan program analisis struktur.

Graphis user interface dari ENGILAB BEAM digunakan untuk merancang, menganalisa, mendesain, dan menampilkan geometri struktur, properti dan hasil analisis. Prosedur dari analisis ini dapat dibagi ke dalam 3 (tiga) bagian, yaitu : (Haryanto, 2001).

1. Preprocessing (Pra Proses).

2. Solving (Penyelesaian).
3. Post Processing (Pasca Proses)

Analisa penampang yang dilakukan pada redesain perencanaan struktur gedung ini meliputi analisa kolom dan balok yang mengacu pada Standar Tata Cara Penghitungan Struktur Beton Untuk Bangunan Gedung (SK-SNI T-15-03-1991), Standar Tata Cara Perhitungan Struktur Beton untuk Bangunan Gedung (SNI 032847-2002), Peraturan Beton Bertulang Indonesia tahun 1971 dan didasarkan pada hasil dari analisa struktur yang telah dilakukan sebelumnya dengan menggunakan porgram dari ENGILAB BEAM.

\subsection{Dilatasi}

Dilatasi adalah sebuah sambungan / garis pada sebuah bangunan yang dikarenakan sesuatu hal memiliki sistem struktur berbeda. Dilatasi digunakan pada pertemuan antara bangunan yang rendah dengan yang tinggi, antara bangunan induk dengan bangunan sayap, dan bagian bangunan lain yang mempunyai kelemahan geometris.

\subsection{Rencana Anggaran Biaya (RAB)}

Rencana anggaran biaya merupakan perkiraan biaya yang diperlukan untuk setiap pekerjaan dalam suatu proyek konstruksi sehingga akan diperoleh biaya total yang diperlukan untuk suatu proyek. Rencana anggaran biaya (begrooting) suatu bangunan atau proyek adalah perhitungan banyaknya biaya yang diperlukan untuk bahan dan upah, serta biaya-biaya lain yang berhubungan dengan pelaksanaan bangunan atau proyek tersebut (Bachtiar Ibrahim 1993).

Anggaran biaya merupakan harga dari bangunan yang dihitung dengan teliti, cermat dan memenuhi syarat. Anggaran biaya pada bangunan yang samaakan berbeda-beda di masing-masing daerah, disebabkan karena perbedaan harga bahan dan upah tenaga kerja. Pembuatan rencana anggaran biayaakan membuat penaksiran harga barang dan upah, penaksiran anggaran biaya sangat diperlukan dalam perhitungan rencana anggaran biaya, dimana pengertian penaksiran anggaran biaya adalah suatu proses perhitungan volume pekerjaan, sehingga harga-harga bahan yang diperlukan dalam pekerjaan konstruksi. Biaya (anggaran) adalah jumlah dari masingmasing hasil perkiraan volume dengan harga satuan pekerjaan yang bersangkutan.

\section{METODOLOGI PENELITIAN}

Metodologi penelitian yang digunakan adalah studi pustaka. Dalam Tugas Akhir ini dibutuhkan tahapan pengerjaan yang teratur dan sistematis agar mendapatkan hasil yang 
sesuai dengan harapan di akhir penyusunan. Selain tahapan pengerjaan juga dijelaskan mengenai rencana kerja. Diagram alir penelitian dan rencana kerja (flowchart) dapat dilihat dibawah ini.

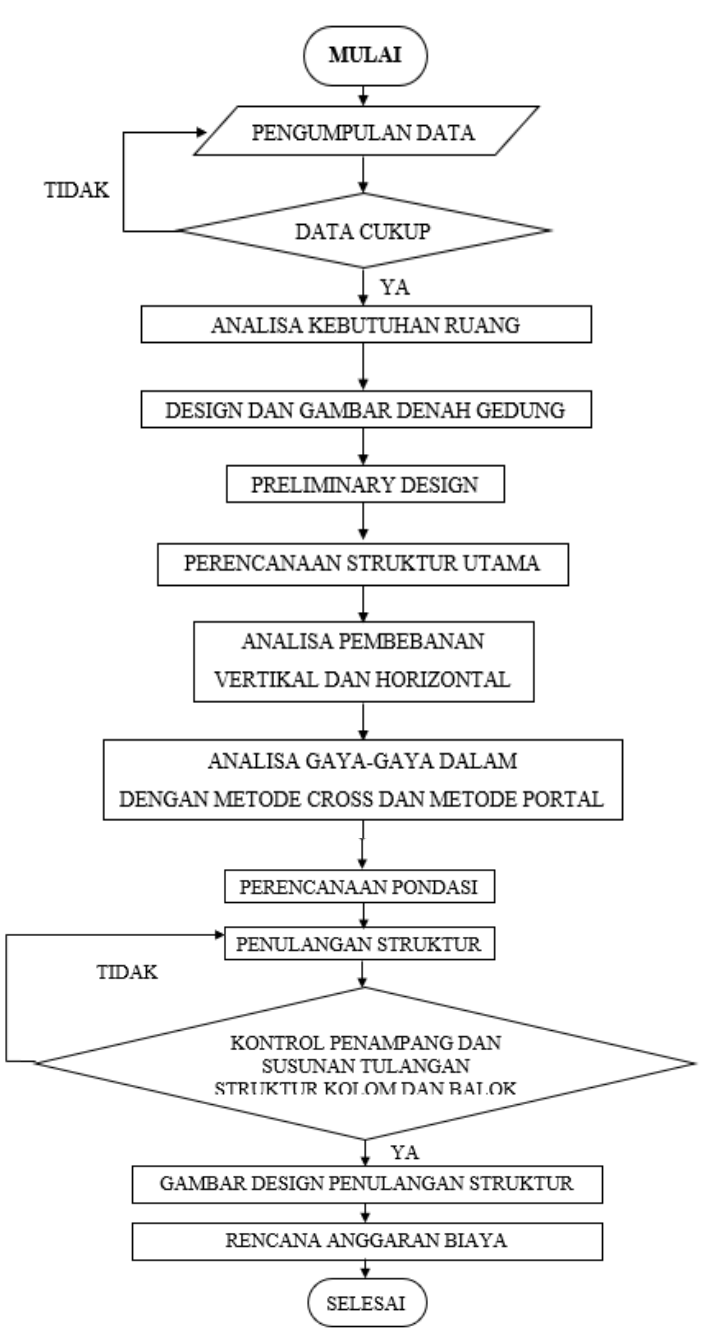

Gambar 1. Flowchart Analisis dan Perencanaan Gedung

\section{HASIL DAN PEMBAHASAN}

\subsection{Kebutuhan Ruang}

Kebutuhan ruangan pada Asrama Putri desa Sei Raya, Time Saver Standard (TSS), dan Asumsi (AS).

Tabel 1. Analisa Rencana Kebutuhan Ruang

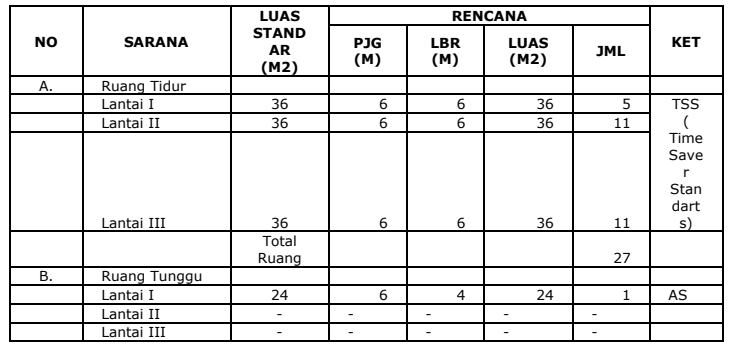

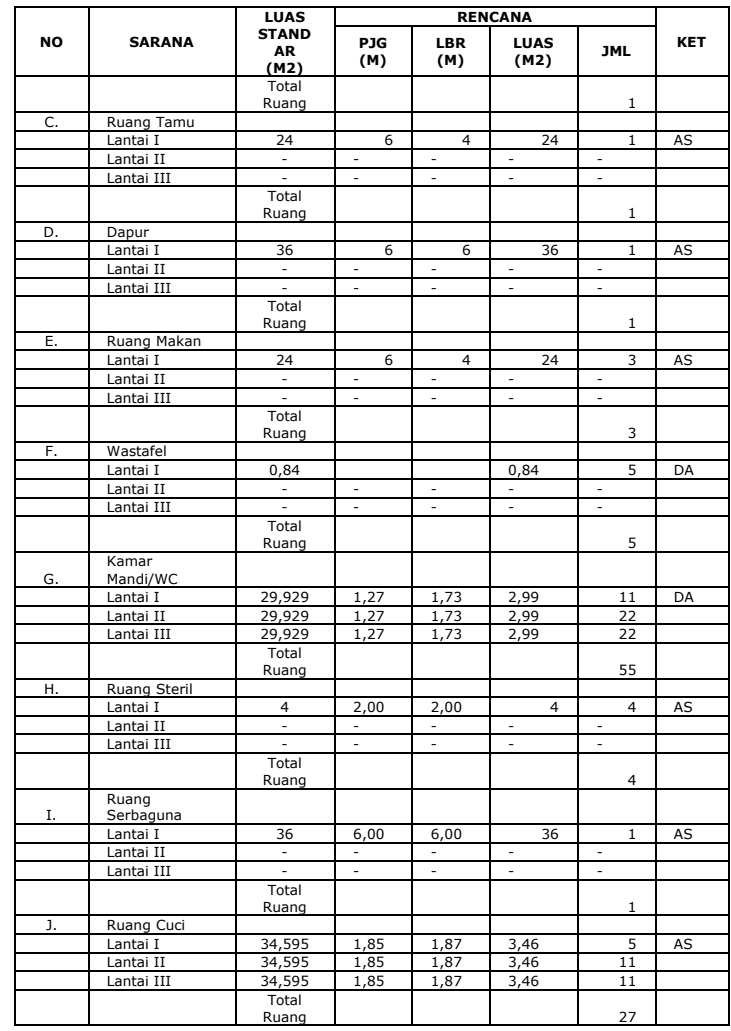

\subsection{Preliminary Design}

Preliminary design berupa pendekatan perencanaan dengan asumsi yang disesuaikan dengan peraturan yang berlaku pada Standar Nasional Indonesia (SNI 03 - 2847 - 2002) Tata Cara Perhitungan Struktur Beton Untuk Bangunan Gedung, Standar Nasional Indonesia (SNI 2847:2013) persyaratan beton struktural untuk bangunan gedung dan SKSNI T-15-199103. Hasil penentuan dari preliminary design di analisa sehingga seluruh komponen struktur diharapakan dapat mencapai hasil perencanaan yang efisien.

\subsection{Analisa Pembebanan}

Analisa pembebanan dilakukan berdasarkan peraturan pembebanan Indonesia atau berdasarkan Standar Nasional Indonesia untuk gedung berlantai banyak/gedung bertingkat. Tabel 2. Analisa Pembebanan.

\begin{tabular}{|c|c|c|c|c|c|c|c|}
\hline \multirow[t]{2}{*}{ No } & \multirow[t]{2}{*}{ Lantai } & \multicolumn{3}{|c|}{$\underset{(\mathrm{cm})}{\text { Dimensi }}$} & \multirow{2}{*}{$\begin{array}{l}\text { Beban } \\
\text { Hidup } \\
\mathrm{Kg} / \mathrm{m}^{2}\end{array}$} & \multicolumn{2}{|c|}{$\begin{array}{c}\text { Beban Mati } \\
\text { Bahan \& } \\
\text { Konstruksi }\end{array}$} \\
\hline & & Pjg & Lbr & $t$ & & $\mathrm{Kg} / \mathrm{m}^{2}$ & $\mathrm{Kg} / \mathrm{m}^{3}$ \\
\hline $\mathbf{A}$ & SATU/DASAR & & & & & & \\
\hline 1 & Kolom $40 / 40 \mathrm{~cm}$ & 400 & 40 & 40 & & & 2400 \\
\hline 2 & Kolom $12 / 12 \mathrm{~cm}$ & 400 & 12 & 12 & & & 2400 \\
\hline 3 & Balok B1 $35 / 50 \mathrm{~cm}$ & & 35 & 50 & & & 2400 \\
\hline 4 & Lantai & & & 12 & & & 2400 \\
\hline 5 & Keramik & & & 1 & & 24 & \\
\hline 6 & Spesi & & & 3 & & 21 & \\
\hline 7 & Mekanikal Elektrikal & & & & & 10 & \\
\hline 8 & Plafond + Penggantung & & & & & 17 & \\
\hline 9 & Beban Hidup & & & & 250 & & \\
\hline B & DUA & & & & & & \\
\hline 1 & Kolom 40/40 cm & 400 & 40 & 40 & & & 2400 \\
\hline 2 & Kolom $12 / 12 \mathrm{~cm}$ & 400 & 12 & 12 & & & 2400 \\
\hline 3 & Balok B1 $35 / 50 \mathrm{~cm}$ & & 35 & 50 & & & 2400 \\
\hline
\end{tabular}




\begin{tabular}{|c|c|c|c|c|c|c|c|}
\hline \multirow[t]{2}{*}{ No } & \multirow[t]{2}{*}{ Lantai } & \multicolumn{3}{|c|}{$\underset{(\mathrm{cm})}{\text { Dimensi }}$} & \multirow{2}{*}{$\begin{array}{l}\text { Beban } \\
\text { Hidup } \\
\mathrm{Kg} / \mathrm{m}^{2}\end{array}$} & \multicolumn{2}{|c|}{$\begin{array}{l}\text { Beban Mati } \\
\text { Bahan \& } \\
\text { Konstruksi }\end{array}$} \\
\hline & & Pjg & Lbr & $t$ & & $\mathrm{Kg} / \mathrm{m}^{2}$ & $\mathrm{Kg} / \mathrm{m}^{3}$ \\
\hline 4 & Lantai & & & 12 & & & 2400 \\
\hline 5 & Keramik & & & 1 & & 24 & \\
\hline 6 & Spesi & & & 3 & & 21 & \\
\hline 7 & Mekanikal Elektrikal & & & & & 10 & \\
\hline 8 & Plafond + Penggantung & & & & & 17 & \\
\hline 9 & Beban Hidup & & & & 250 & & \\
\hline c & TIGA & & & & & & \\
\hline 1 & Kolom $40 / 40 \mathrm{~cm}$ & 400 & 40 & 40 & & & 2400 \\
\hline 2 & Kolom $12 / 12 \mathrm{~cm}$ & 400 & 12 & 12 & & & 2400 \\
\hline 3 & Balok B1 $35 / 50 \mathrm{~cm}$ & & 35 & 50 & & & 2400 \\
\hline 4 & Lantai & & & 12 & & & 2400 \\
\hline 5 & Keramik & & & 1 & & 24 & \\
\hline 6 & Spesi & & & 3 & & 21 & \\
\hline 7 & Mekanikal Elektrikal & & & & & 10 & \\
\hline 8 & Plafond + Penggantung & & & & & 17 & \\
\hline 9 & Beban Hidup & & & & 250 & & \\
\hline D & EMPAT/DUG & & & & & & \\
\hline 1 & Balok B2 35/50 cm & & 35 & 50 & & & 2400 \\
\hline 2 & Lantai Dug & & & 10 & & & 2400 \\
\hline 3 & Air Hujan & & & 1 & & & 1000 \\
\hline 4 & Mekanikal Elektrikal & & & & & 10 & \\
\hline 5 & Plafond + Penggantung & & & & & 17 & \\
\hline 6 & Beban Hidup & & & & 100 & & \\
\hline
\end{tabular}

Analisa pembebanan akibat beban vertikal dan beban horizontal ditinjau dari denah rencana gedung yang terdiri dari 3 lantai, area pembebanan dapat dilihat dari gambar denah dibawah ini:

1. Koefisien reduksi beban hidup Iantai sekolah

a. Koefisien reduksi beban gravitasi $=0,75$

b. Koefisien reduksi beban gempa $=0,3$

2. Wilayah gempa $=1$

3. Jenis tanah $=$ Tanah lunak

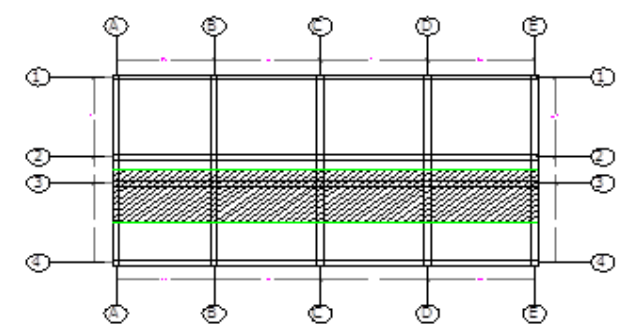

Gambar 2. Denah Pembebanan Gedung I

\subsection{Analisa Struktur}

Analisa gaya-gaya dalam pada struktur portal yang dianalisa akibat pembebanan menggunakan Metode Egilab.

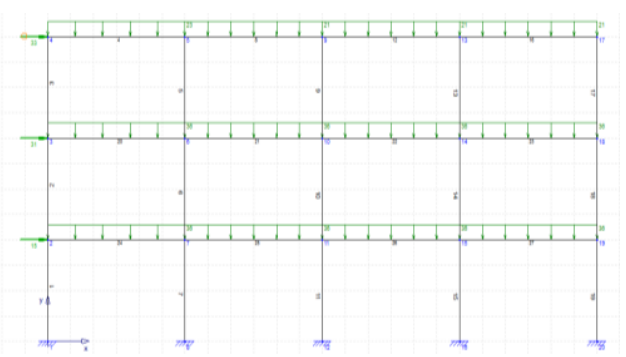

Gambar 3. Hasil Analisa Struktur dengan menggunakan Aplikasi Engilab Beam Gedung 1

\subsection{Perencanaan Pondasi}

Pondasi yang dipakai pada perencanaan Gedung ini menggunakan pondasi tiang pancang (Mini Pile). Hal ini berdasarkan dari data tanah yang didapat dengan menggunakan alat sondir. Sondir yang diperhitungkan pada desain pondasi ini pada kedalaman $18 \mathrm{~m}$ dengan nilai (qc) $\geq 110$ $\mathrm{kg} / \mathrm{cm}^{2}$. Tiang pancang yang digunakan adalah panjang 6 meter, maka yang digunakan dalam perencanaan ini adalah pada kedalaman 18 meter. Dimensi mini pile adal h $20 \mathrm{~cm} \times 20 \mathrm{~cm}$. nilai konis pada kedalaman $18 \mathrm{~m}$ adalah 110 $\mathrm{kg} / \mathrm{cm}^{2}$ dan shear resistancenya $708,8 \mathrm{~kg} . \mathrm{cm}^{2}$. angka keamanan untuk pondasi adalah 3 pada daya dukung ujung dan 5 untuk daya dukung selimut. Luas penampang alah $400 \mathrm{~cm}^{2}$.

\subsection{Dimensi Struktur}

Dimensi struktur pada design gedung asrama ini, terdiri dari :

Tabel 3. Dimensi Struktur

\begin{tabular}{|l|l|l|}
\hline \multirow{3}{*}{ Lantai } & $\begin{array}{l}\text { Dimensi } \\
\text { Kolom }\end{array}$ & $\begin{array}{l}\text { Dimensi } \\
\text { Balok }\end{array}$ \\
\cline { 2 - 3 } & $(\mathrm{Cm})$ & $(\mathrm{Cm})$ \\
\hline Satu & $40 \times 40$ & $35 \times 50$ \\
\hline Dua & $40 \times 40$ & $35 \times 50$ \\
\hline Tiga & $40 \times 40$ & $35 \times 50$ \\
\hline Atap/Dug & & $35 \times 50$ \\
\hline
\end{tabular}

\subsection{Rencana Anggaran Biaya}

Rencana anggaran biaya (RAB) adalah tolak ukur dalam perencanaan pembangunan, baik rumah tinggal, ruko, rukan maupun gedung lainya. Dengan RAB kita dapat mengukur kemampuan materi dan mengetahui jenis-jenis material dalam pembangunan, sehingga biaya yang kita keluarkan lebih terarah dan sesuai dengan yang telah direncanakan.

\section{KESIMPULAN}

Hasil kajian yang telah dilaksanakan dapat dicimpulkan bahwa:

1. Kebutuhan Ruangan yang diperlukan adalah dengan total ruang berjumlah 70 ruang yang terdiri dari kamar tidur santriwati, kamar tidur ustadzah, kamar mandi ustadzah dan santriwati, ruang belajar, ruang jemur, ruang makan, dapur, ruang sterilisasi dan gudang.

2. Hasil dimensi serta penulangan yang direncanakan berdasarkan tinjauan analisa perhitungan struktur kolom dan balok adalah sebagai berikut :

a. Dimensi kolom yang direncanakan 40 $x 40 \mathrm{~cm}$

b. Dimensi balok sloof yang direncanakan $40 \times 40 \mathrm{~cm}$ 
c. Dimensi balok yang direncanakan $35 \mathrm{x}$ $50 \mathrm{~cm}$

3. Perencanaan struktur gedung bertingkat menggunakan bahan material beton bertulang

4. Hasil perhitungan rencana anggaran biaya perencanaan gedung adalah Rp. 5.276.365.316,00 (Lima Miliyar Dua Ratus Tujuh Puluh Enam Juta Tiga Ratus Enam Puluh Lima Ribu Tiga Ratus Enam Belas Rupiah)

\section{DAFTAR PUSTAKA}

[1] A.Soedjarajat Sastraatmaja, 1984 Analisa Anggaran Biaya Pelaksanaan, Penerbit Nova Bandung.

[2] Adiyono, 2006, Menghitung Konstruksi Beton, Penebar Swadaya, Jakarta, 2006.

[3] Alle, Edward, 2005, Dasar-dasar Konstruksi bangunan : Bahan-bahan dan metodenya,

[4] Angreni, Ida Ayu Ari. "Perhitungan Rencana Anggaran Biaya Banh-Gunan Gedung Dengan Perbandingan Harga Satuan Kontraktor". Jurnal Ilmiah Desain Dan Kontruksi Vol 10, No.01. 2011. Hal 1.

[5] Arsoni A, Balok dan Pelat Beton Bertulang, Graha IImu, Yogyakarta 2010

[6] BSN, 2013. Persyaratan Beton Struktural Untuk Bangunan Gedung SNI 2847:2013, Badan Standardisasi Nasional, Jakarta

[7] Budiono, B. 2011. Struktur Beton Bertulang I. Catatan Kuliah. ITB, Bandung.

[8] Budiono, B. 2011. Struktur Beton Bertulang. Catatan Kuliah. ITB, Bandung.

[9] Destika, K. 1999. Perencanaan Struktur Gedung FBPS IKIP Padang. Skripsi, Padang.

[10] Dewobroto W, Aplikasi Rekayasa Konstruksi dengan ENGILAB BEAM 2000 Edisi Baru, Elex Media Komputindo, Jakarta 2007

[11] DPMB, 1971. Peraturan Beton Bertulang Indonesia N.-2, Direktorat Penyelidikan Masalaha Bangunan, Bandung.

[12] DPPW, 2002. Standar Perencanaan Ketahanan Gempa Untuk Struktur Bangunan Gedung SNI-1726-2002. Departemen Permukiman dan Prasarana Wilayah, Bandung.

[13] DPPW, 2003. Standar Perencanaan Ketahanan Gempa Untuk Struktur Bangunan Gedung SNI 03-1726-2003. Departemen Permukiman dan Prasarana Wilayah, Bandung.

[14] DPU, 1991. Tata Cara Perhitungan Struktur Beton Untuk Bangunan Gedung
SK SNI T-15-1991-03, Yayasan Lembaga Penyelidikan Masalah Bangunan, Bandung.

[15] DPU, 2002. Tata Cara Perhitungan Struktur Beton Untuk Bangunan Gedung SNI 03-2847-2002. Departemen Pekerjaan Umum, Bandung.

[16] Ervianto, Wulfram, 2004, Soal \& Penyelesaian Analisa Struktur Statik Tertentu,

[17] Frick, Heinz, Ir. 1978, Mekanika Teknik 1 \& 2, Kanisius, Yogyakarta, 2007

[18] Gere \& Timoshenko, Mekanika Bahan Jilid I \& II, Erlangga, Jakarta 2000

[19] Gunawan. T, Ir. dan Margaret. S, Ir. 1994. Diktat Teori Soal dan Penyelesaian Mekanika Teknik IV, Jilid I dan II, Delta Teknik Group Jakarta

[20] Hibbeler, R, C, Structural Analysis, Printed the United States Of Amerika 1995

[21] Ibrahim, H.Bachtiar.1993. Rencana Dan Estimate Real Of Cost.Cetakan Ke-2. Jakarta : Bumi Aksara.

[22] Imron, I . 2011. Struktur Beton. Catatan Kuliah. ITB, Bandung.

[23] Imron, I. 2011. Sruktur Beton II. Catatan Kuliah. ITB, Bandung.

[24] Karlen, Mark, dan Benya, James, Dasardasar Desain Pencahayaan, Erlangga, 2006

[25] Karlen, Mark, Dasar-dasar Perencanaan Ruang, Edisi Kedua, Erlangga, 2007

[26] L. Taulu, Ir, dkk, Mekanika Tanah dan Teknik Pondasi, Pradnya Paramita, Jakarta, 1981

[27] LPMB, 1983. Peraturan Pembebanan Indonesia Untuk Gedung, Yayasan Lembaga Penyelidikan Masalah Bangunan, Bandung.

[28] LPMB, 1987. Pedoman Perencanaan Pembebanan Untuk Rumah dan Gedung, Yayasan Lembaga Penyelidikan Masalah Bangunan, Bandung.

[29] Mulyadi, Meli. "Asrama Mahasiswa Universitas Tanjungpura". Jurnal online mahasiswa Arsitektur, Universitas Tanjungpura Vol.6 No.1, 2018, Hal 4

[30] Nuryanto, Wahyu, 2012, "Redesign Struktur Kolom Dan Balok Pada Perencanaan Gedung Perkuliahan Universitas Islam Indragiri Tembilahan", Tugas Akhir Mahasiswa, Universitas Diponegoro.

[31] Oentoeng, Ir. 1999, Konstruksi Baja, Andi Yogyakarta

[32] Pratama Tangguh, Putra. 2014. "Peranan Pondok Pesantren Hudatul Muna II Ponorogo dalam penegmbangan pendidikan santri untuk menghadapi tantangan di era globalisasi", Skripsi Mahasiswa, UIN Sunan Ampel Surabaya. 
[33] Purwono R, Prof, Ir, M.Sc, Perencanaan Struktur Beton Bertulang Tahan Gempa, Itspress, 2010

[34] Riza, Muhammad, 2006, "Perencanaan Struktur Gedung Swalayan Ramai Semarang", Tugas Akhir Mahasiswa, Universitas Diponegoro.

[35] Rosa, A. 2005. Konstruksi Beton II. Tugas Besar. STTI, Rengat.

[36] Siddiq, Umar. 2013. "Pengembangan Standarisasi Pondok Pesantren". Jurnal. Sekolah Tinggi Agama Islam Negeri Ponorogo

[37] Sunggono kh. Ir, 1995, Buku Teknik Sipil, Nova Bandung.

[38] T. Gunawan, Ir, Dkk, Struktur Beton Bertulang, Delta Teknik, 1999

[39] Taulu L, Ir, Mekanika Tanah dan Teknik Pondasi, Pradnya Paramita, 1981

[40] Wulandari. Ratri, "Analisa Kaitan Desain Asrama Dengan Perilaku Penghuni Melalui Studi Analisa Konten Penelitian Sejenis". Jurnal I D E A L O G, Ide Dan Dialog Indonesia Vol. 1 No. 3, 2016, Hal 4

[41] Zainuri, Muhib, Ach, ST, Kekuatan Bahan, Andi, Yogyakarta,

[42] Antonius, 2001. "Bahan Ajar Struktur berton". https://sanggapramana.wordpress.com/category/perhitunganbalok/. Htm > (Accessed 03 Februari 2017)

[43] Nt, Suyono. 1983. "Rangkuman Pedoman Perencanaan Pembebanan Untuk Rumah dan Gedung". http://sipil.polsri.ac.id/Download/CodePeraturan-Pedoman /PPPURG_1987.pdf. $\mathrm{Htm}>$ (Accessed 03 Februari 2017).

[44] Anamois. "Bab II Landasan Teori". http://repository.usu.ac.id/bitstream/12 3456789

[45] /19261/3/Chapter\%20II.pdf. Htm > (Accessed 05 Januari 2012 ).

[46] Anamois. "Bab II Teori Dasar". http://repository.usu.ac.id/bitstream $/ 123456789 / 21$

[47] 076/3/Chapter\%20II.pdf. Htm > (Accessed 05 Januari 2012 ). 